Original Article

\title{
The effect of age on hamstring passive properties after a 10-week stretch training
}

\author{
Thomas HaAB, MSc $\left.{ }^{1,2}\right)^{*}$, Georg Wydra ${ }^{1)}$ \\ 1) Sport Science Institute, Saarland University: Geb. B 8.1, 66041 Saarbruecken, Germany \\ 2) Lunex University, Luxembourg
}

\begin{abstract}
Purpose] Degenerative changes take place in the musculoskeletal system of elderly people, resulting in a reduced range of motion. For this reason, stretch training is recommended for elderly individuals. To date, there have been no studies of the adaptations of the passive properties of muscles following long-term stretch training. The aim of this study is to investigate the hamstring elasticity of elderly people following a 10 -week stretch training and compare the results to a younger cohort. [Subjects and Methods] The experimental groups consisted of 15 younger $(24.0 \pm 4.0$ years $)$ and 14 older $(65.1 \pm 7.9$ years $)$ individuals. Both experimental groups undertook a standardised 10-week static passive hamstring stretch training. Passive properties of the hamstring were measured with an instrumented Straight Leg Raise Test. [Results] After a 10-week stretch training, there were increases in range of motion, passive resistive force and passive elastic energy in both age groups. Passive elastic stiffness decreased. Changes of hamstring passive properties did not differ significantly between age groups after a 10 -week stretch training. [Conclusion] Increasing age has a negative effect on muscle passive properties, but older individuals benefit from regular stretch training, just as younger individuals do.

Key words: Age, Stretching, Skeletal muscle
\end{abstract}

(This article was submitted Feb. 6, 2017, and was accepted Mar. 20, 2017)

\section{INTRODUCTION}

In general, the primary goal of stretch training is to extend the range of motion (RoM). RoM is manifested as the range of motion of a joint system and thus depends on the extensibility of the skeletal muscles, tendons and ligaments as well as limitations by structural anatomical characteristics ${ }^{1)}$. Most studies measure the effects of stretch training in terms of range of motion. Without analysing a stress-strain curve, however, no conclusions can be drawn about the changes in the muscles' passive properties. The stress-strain curve reflects the passive property of the muscle-tendon unit (MTU) during a stretch by depicting the changes in the range of motion (RoM angle) against tensile stress. If a muscle is stretched, the result is a stressstrain curve with an exponential rate of increase that has three characteristic properties ${ }^{2}$. In the first section of the curve, the toe region, a very minimal stretch results in activation of wave-form collagen fibres ${ }^{3,4)}$. The second section of the curve is known as the elastic region and follows a linear increase. In this region, a tensile force results in a reversible deformation of the tissue. Once the tensile force is relaxed, the tissue immediately returns to its original position ${ }^{5}$. The third section of the curve is the plastic region. This section is the result of an ever-increasing stretch that extends beyond the elastic properties of the structures. Up to a certain point (the yield point), the tissue continues to be deformed up to a stress limit, beyond which point the deformation is irreversible. When a muscle is stretched in a training session, it is extended as far as the elastic region so that the maximum muscle extension is accompanied by the maximum tensile stress that a subject can tolerate. The maximum range of motion and maximum tensile stress in turn depend on the maximum stretch pain that can be endured ${ }^{6,7)}$.

Degenerative changes in the musculoskeletal system and changes in the neuromuscular system that occur with increasing

*Corresponding author. Thomas Haab (E-mail: thomas.haab@uni-saarland.de)

(C2017 The Society of Physical Therapy Science. Published by IPEC Inc.

This is an open-access article distributed under the terms of the Creative Commons Attribution Non-Commercial No Derivatives (by-nc-nd) License $<$ https://creativecommons.org/licenses/by-nc-nd/4.0/>. 
age affect a person's RoM ${ }^{8-10}$. Although a study by Ryan et al. ${ }^{11)}$ found that older adults have a smaller RoM than younger adults, both groups showed similar rates of growth in terms of maximum range of motion and maximum tensile stress shortly after muscle stretches. While a relationship between muscle elasticity and age was demonstrated, the ability to affect RoM with training appears to be unrelated to age ${ }^{12)}$.

The ability to train a muscle as measured in terms of elasticity and range of motion has not been studied to date over a longer period in elderly subjects. The aim of this study is to compare the changes of passive properties of the hamstring after a 10 -week standardised stretch training in younger versus older individuals. The hamstring muscles were chosen, as these pass between two articulated structures, the hip and the knee. By fixing the hip in a backward position, the hamstring can be stretched to a maximum in a straight-leg raise test without the disruptive effect of the bones (joint system) or inhibition of mass from other muscle groups.

\section{SUBJECTS AND METHODS}

This study was carried out in accordance with the Declaration of Helsinki and was reviewed and approved by the Ethics Committee of Faculty 5, Empirical Human Sciences of Saarland University (Application 15-5). All participants were provided with an information sheet describing the benefits and risks of the study. Participants signed an informed consent form that indicated that participation is voluntary, and they were free to withdraw from the study at any time. Processing of participant information and all study data took place in anonymised form so that it is impossible to draw conclusions about specific persons in retrospect.

The required sample size was determined a priori using the program $G^{*}$ Power (Kiel University, Version 3.1.9.2) ${ }^{13}$. The sample size was also based on other similar experimental studies ${ }^{14,15)}$. An $\alpha$-level of 0.05 and a power $(1-\beta)$ of 0.8 were used. A total of ten subjects per experimental group were required for the analyses (one group of elderly adults, one group of younger adults). To account for the possibility of dropouts, 15 younger and 14 older adults were recruited. The younger group consisted of students in their fourth semester of sport science studies; the older participants were recruited from a preventative sports group at Saarland University. All participants were male. The following exclusion criteria applied to both experimental groups: (a) hip and/or knee pain, (b) pain in the hamstrings, (c) hip or knee prosthesis, (d) acute back pain ( $<3$ months), (d) current or previous hip or knee injuries, (e) current hamstring injuries and (f) involvement in sports with a high degree of joint mobility. Further, participants were not to be involved if they did sports for more than 60 minutes per day for more than three days per week. As per the criteria of Hoge et al. ${ }^{16)}$, participants therefore qualified as recreational athletes. Participants were also instructed to follow their usual lifestyle habits throughout the duration of the study and avoid any unusual physical activity. After excluding dropouts, a total of 12 elderly adults (age: $65.1 \pm 7.9$ years, height: $178.8 \pm 6.1 \mathrm{~cm}$, weight: $81.9 \pm$ $8.0 \mathrm{~kg}$ ) and 13 younger adults (age: $24.0 \pm 4.0$ years, height: $178.5 \pm 7.2 \mathrm{~cm}$, weight: $75.9 \pm 10.1 \mathrm{~kg}$ ) completed the study and were included in the statistical analyses. One elderly and two younger subjects dropped out prematurely, due to illness. One elderly individual was excluded prior to the end of study, due to lack of compliance.

The study took place over a total of 12 weeks. Participants were habituated to the test situation on two separate familiarisation occasions during the first two weeks; the training phase then followed. Participants undertook a 10-week static passive stretch training regime (three times per week, three repetitions of 60 seconds per leg) of the hamstring. The stress parameters were based on the training recommendations from the American College of Sports Medicine for older adults ${ }^{17,18)}$. Treatment was restricted to the static passive stretch method, since this method is easier for older individuals to accomplish, compared to other stretch methods. Moreover, compliance is expected to be higher if the stretch exercise is easier to perform. Further, among the various stretch methods, the effects in terms of improved range of motion are comparable ${ }^{19}$.

During stretch training, participants stood in front of a chair and extended the leg to be stretched onto the chair. They were to incline the upper body downwards until an intense stretch pain was felt in the back of the upper leg that would be categorised as between seven and eight on a pain scale of 1 to $10(0=$ no stretch pain, $10=$ intolerable stretch pain $)$. Over the 10-week treatment, participants kept a log of activity, noting their stretch training for each week. The activity log also served to monitor compliance. Once or twice per week, the elderly adults visited the preventative sports group at Saarland University and performed their stretches there under supervision as well as at least once at home. During the treatment phase, the younger adults met once per week with study investigators to check the training.

A specially designed instrumented Straight-Leg Raise Test (ISLRT) was used to collect data (Fig. 1). After completing a questionnaire on anthropometric data, participants spent a three-minute warm-up period on a bicycle ergometer (Ergo-Fit, Ergo 1500 Cycle) at a cadence with 70 rounds per minute (RPM) and one watt per kilogram body weight (1 W/kg BW). The intensity was based on the performance level of the older experimental group. The members of this group underwent a medical examination at annual intervals. In some individuals, intensity greater than $1 \mathrm{~W} / \mathrm{kg}$ BW already represented critical stress for the cardiovascular system. Because the warm-up was to be consistent across individuals, this intensity was chosen for both the younger and older groups. A pre-stretching (static passive stretching on their own) of the hamstring $(6 \times 10$ seconds per leg) followed the warm-up to prepare the muscles for a maximum stretch. The pre-stretching consisted of the same exercise as the stretch training during the treatment phase. It has been shown that stiffness of the muscle is affected by a warm-up, known as the warm-up effect ${ }^{20)}$. Hence, to control for this effect in this study, participants undertook a standardised warm-up prior to data collection. Room temperature was measured with a digital thermometer (TFA Dostmann, Wertheim) 


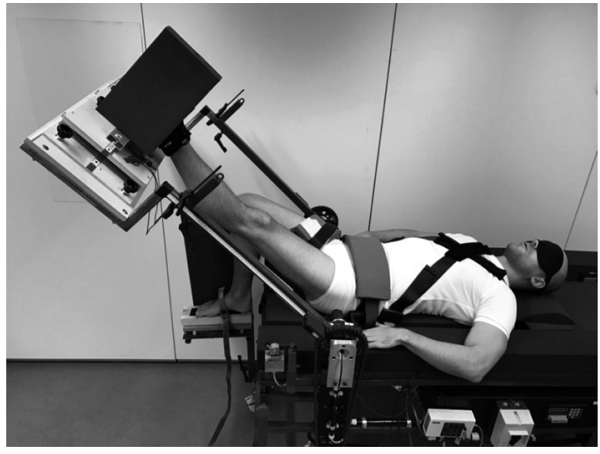

Fig. 1. Instrumented Straight-Leg Raise Test (ISLRT)

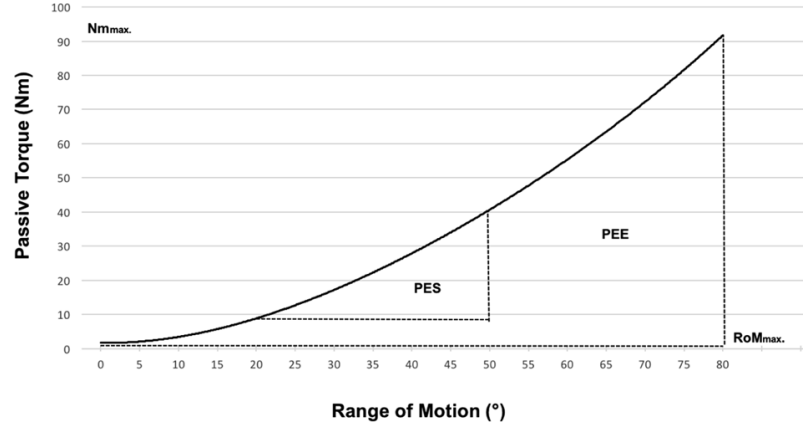

Fig. 2. Example of a stress-strain curve measured during the ISLRT with dependent variables

$\mathrm{Nm}_{\text {max. }}$ : maximum passive torque; $\mathrm{RoM}_{\max }$ : maximum range of motion; PES: passive elastic stiffness as the slope through $20^{\circ}$ and $50^{\circ}$; PEE: passive elastic energy as the area under the stress-strain curve

and was also held constant as far as possible (temperature pre-test: $22.1 \pm 0.9^{\circ} \mathrm{C}$, temperature post-test: $22.0 \pm 1.2{ }^{\circ} \mathrm{C}$ ).

Immediately following the pre-stretch, participants were positioned on the ISLRT (Fig. 1). The participant lay on his back on the ISLRT, and the leg to be tested was positioned with an unbent knee in a horizontal position onto a lever arm. The opposite leg was positioned laterally and fixed, in order to offset lumbar lordosis. The pelvis and upper body were also held in place with belts. The left hamstring was tested during a passive stretch. The participant's eyes were covered with a sleep mask to prevent visual disturbances during the stretch. The ISLRT was controlled by a continuously adjustable electric motor set at a speed of $1.5^{\circ} \mathrm{sec}$. The participant controlled the motor using a 1-way joystick (Saia-Burgess Electronics, Switzerland) and was instructed to stretch the leg passively up to the point when he could extend the stretch no further, due to the pain threshold. The lever arm was then lowered by the participant at a speed of $3.75 \% \mathrm{sec}$., until it reached the horizontal position again. This process was repeated once, and the mean of the two values was calculated.

The perception of pain upon reaching the maximum stretch was objectively assessed on a $100 \mathrm{~mm}$ pain scale, where $0 \mathrm{~mm}$ represents no stretch pain and $100 \mathrm{~mm}$ represents an intolerable stretch pain. The pain scale is shown as a $100 \mathrm{~mm}$ horizontal line, and participants marked a vertical line corresponding to their perception of pain; this took place immediately following the stretch procedure.

Data were recorded with DasyLab Software (National Instruments Ireland Resources Limited, Version 10) with $500 \mathrm{~Hz}$ via a 16-channel A/D converter (Biovision, Wehrheim). The Software synchronously recorded the range of motion (joint angle in ${ }^{\circ}$ ) and the passive resistive force (muscle tension in $\mathrm{N}$ ). To make the passive resistive force comparable among participants, the values were relativised to the individual leg lengths. Leg length was measured as the distance from the floor to the trochanter major. The product of leg length and the measured passive resistive force yielded the passive torque (Nm), and this calculated value was used for the statistical analyses. Joint angle was measures using a potentiometer (Biovision, Wehrheim) mounted within the ISLRT rotary axis. Passive resistive force used to determine passive torque was measured using a special foot construction with force transducers (Biovision, Wehrheim) ${ }^{21)}$. Calculation of passive torque was corrected for leg weight and gravity. The stress-strain curve was smoothed using a fourth-order polynomial.

The dependent variables are the maximum range of motion $\left(\mathrm{RoM}_{\max }\right)$ and the maximum passive torque $\left(\mathrm{Nm}_{\max }\right)$. According to Marshall et al. ${ }^{22)}$, passive elastic stiffness (PES) was also calculated as the slope through $20^{\circ}$ and $50^{\circ}$ range of motion (hip flexion angle). The area under the stress-strain curve was used as a measure of the passive elastic energy (PEE). The dependent variables are shown in Fig. 2.

The data were analysed using the program MatLab (MathWorks Inc., Version R2014a), and statistical calculations were carried out using SPSS (IBM Corp., Version 23). In a pilot study involving 16 participants (age: $25.3 \pm 3.6$ years, height: $176.1 \pm 7.6 \mathrm{~cm}$, weight: $69.7 \pm 7.1 \mathrm{~kg}$ ), reliability of the dependent variables was high with Pearson correlation coefficients: $\operatorname{RoM}_{\text {max. }}(\mathrm{r}(14)=0.94, \mathrm{p}<0.001) ; \mathrm{Nm}_{\text {max. }}(\mathrm{r}(14)=0.90, \mathrm{p}<0.001)$; $\operatorname{PES}(\mathrm{r}(14)=0.93, \mathrm{p}<0.001)$; $\operatorname{PEE}(\mathrm{r}(14)=0.89 ; \mathrm{p}<0.001)$.

Differences between age groups in the dependent variables over the baseline were calculated with independent t-tests. Two-factor variance analysis with repeated measurements was performed for each dependent variable. The level of significance was set at an $\alpha$-level of $\mathrm{p} \leq 0.05$. Results are shown as mean \pm standard deviation and are listed with effect sizes (d) according to Cohen $^{23)}$. 
Table 1. Results for dependent variables from younger age group $(n=13)$ and older age group $(n=12)$ at preand post-test

\begin{tabular}{|c|c|c|c|c|}
\hline & \multirow[t]{2}{*}{ Age } & \multicolumn{2}{|c|}{ Time } & \multirow[t]{2}{*}{$\Delta \%$} \\
\hline & & Pre-Test & Post-Test & \\
\hline \multirow{2}{*}{$\mathrm{RoM}_{\max .}\left({ }^{\circ}\right)$} & Young & $93.0 \pm 15.4$ & $101.4 \pm 13.0 * *$ & $+9.9 \pm 7.8$ \\
\hline & Old & $86.7 \pm 14.9$ & $94.7 \pm 15.7 * *$ & $+9.5 \pm 5.9$ \\
\hline \multirow{2}{*}{$\mathrm{Nm}_{\text {max. }}(\mathrm{Nm})$} & Young & $103.1 \pm 45.4$ & $126.4 \pm 43.1 * *$ & $+29.0 \pm 24.0$ \\
\hline & Old & $90.6 \pm 33.1$ & $108.1 \pm 36.1 * *$ & $+21.8 \pm 16.4$ \\
\hline \multirow{2}{*}{$\operatorname{PES}\left(\mathrm{Nm}^{\circ}\right)$} & Young & $0.6 \pm 0.2$ & $0.6 \pm 0.2$ & $-4.6 \pm 11.9$ \\
\hline & Old & $0.7 \pm 0.2$ & $0.6 \pm 0.1$ & $-5.1 \pm 13.0$ \\
\hline \multirow{2}{*}{$\operatorname{PEE}\left({ }^{\circ} \mathrm{Nm}\right)$} & Young & $3,484.8 \pm 1,912.0$ & $4,441.7 \pm 1,835.9 * *$ & $+37.9 \pm 29.0$ \\
\hline & Old & $2,874.0 \pm 1,348.6$ & $3,324.3 \pm 1,644.2 *$ & $+17.5 \pm 27.9$ \\
\hline
\end{tabular}

$\mathrm{Nm}_{\max }$ : maximum passive torque; $\mathrm{RoM}_{\max }$ : maximum range of motion; PES: passive elastic stiffness; PEE: passive elastic energy; $\Delta \%$ : percent change values from pre- to post-test

$* *$ Indicates $\mathrm{p}<0.001$ from pre-test, $*$ Indicates $\mathrm{p}<0.05$ from pre-test

\section{RESULTS}

The results of pre- and post-test for the age groups are shown in Table 1. The dependent variables did not differ significantly between age groups over pre-test: $\operatorname{RoM}_{\text {max. }}(\mathrm{t}(23)=1.04, \mathrm{p}=0.31) ; \mathrm{Nm}_{\max }(\mathrm{t}(23)=0.78, \mathrm{p}=0.44) ; \operatorname{PES}(\mathrm{t}(23)=0.05$, $\mathrm{p}=0.96) ; \operatorname{PEE}(\mathrm{t}(23)=1.35, \mathrm{p}=0.19)$.

A significant main effect for time was found for $\operatorname{RoM}_{\text {max. }}(F(1,23)=56.33, \mathrm{p}<0.001)$. There was no significant age versus time interaction $(\mathrm{F}(1,23)=0.03, \mathrm{p}=0.86)$. At pre- and post-test, the younger age group achieved higher RoM $\mathrm{M}_{\max }$. values compared to the older age group. However, the main effect for age was not significant $(F(1,23)=1.25, p=0.28)$. The older age group showed a similarly large change in the maximum range of motion between pre- and post-test compared to the younger age group (Table 1). A moderate effect size was found between pre- and post-measurements for both age groups $\left(\mathrm{d}_{\mathrm{young}}=0.59\right.$, $\left.\mathrm{d}_{\text {old }}=0.53\right)$.

A significant main effect for time was found for $\mathrm{Nm}_{\text {max. }}(\mathrm{F}(1,23)=57.99, \mathrm{p}<0.001)$. There was no significant age versus time interaction $(\mathrm{F}(1,23)=1.21, \mathrm{p}=0.28)$. At pre- and post-test, the younger age group achieved higher $\mathrm{Nm}_{\max }$. values compared to the older age group. However, the main effect for age was not significant $(F(1,23)=0.96, p=0.34)$. The younger age group increased maximum passive torque more than the older age group (Table 1). A moderate effect size was found between pre- and post-measurements for both age groups $\left(\mathrm{d}_{\text {young }}=0.53, \mathrm{~d}_{\text {old }}=0.50\right)$.

A significant main effect for time was found for PES $(\mathrm{F}(1,23)=4.80, \mathrm{p}<0.05)$. There was no significant age versus time interaction $(\mathrm{F}(1,23)=0.10, \mathrm{p}=0.75)$. At pre- and post-test, the younger and older age group achieved similar PES values. The main effect for age was not significant $(\mathrm{F}(1,23)=0.46, \mathrm{p}=0.51)$. The older age group reduced stiffness between $20^{\circ}$ and $50^{\circ}$ hip flexion angle more than the younger age group (Table 1). A small effect size was found between pre- and postmeasurements for both age groups $\left(\mathrm{d}_{\text {young }}=0.25, \mathrm{~d}_{\text {old }}=0.32\right.$ ).

A significant main effect for time was found for $\operatorname{PEE}(F(1,23)=30.25, \mathrm{p}<0.001)$. There was no significant age versus time interaction $(\mathrm{F}(1,23)=3.92, \mathrm{p}=0.06)$. At pre- and post-test, the younger age group achieved higher PEE values compared to the older age group. However, the main effect for age was not significant $(F(1,23)=1.46, p=0.24)$. The younger age group achieved a greater percent change in passive elastic energy compared to the older age group (Table 1). A moderate effect size was found between pre- and post-measurements for the younger age group, and a small effect size was found for the older age group $\left(\mathrm{d}_{\text {young }}=0.51, \mathrm{~d}_{\text {old }}=0.30\right)$.

\section{DISCUSSION}

This study investigated the adaptations of the hamstring passive properties that occur following a 10-week static passive stretch training in both younger and older adults. The primary result was that the younger experimental group showed adaptations that were higher or similar to those observed in the older group. However, there were no significant differences between age groups. Both groups achieved similar percent growth rates for maximum range of motion. However, at maximum passive torque, the younger group reached a higher percent change compared to the older group. Ryan et al. ${ }^{11)}$ reported short-term effects following stretching of the calf muscles in elderly persons in which both the range of motion and the maximum passive torque showed greater changes compared to a group of younger individuals. These authors attributed the considerable changes in the elderly participants to an age-dependent change in the muscle-tendon tissue. In contrast, in the present long-term study, the results instead suggested that the individuals in the younger group were better able to tolerate the stretch pain. The maximum range of motion should be correlated with the maximum tolerable perception of stretch pain and, 
hence, should yield a high statistical correlation. In retrospect, the correlation between the percent change in the maximum range of motion and the maximum passive torque was calculated with a Pearson correlation coefficient; the relationship was moderate for the older group $\left(\mathrm{r}_{\text {old }}(10)=0.67, \mathrm{p}<0.05\right)$ and high for the younger group $\left(\mathrm{r}_{\text {young }}(11)=0.92, \mathrm{p}<0.001\right)$. This finding for the correlation coefficients is approximately consistent with the results after an acute stretch intervention ( $\mathrm{r}=0.72)$ found by Ryan et $\mathrm{al}^{11)}$. However, for the younger adults, there was a stronger correlation between maximum range of motion and maximum passive torque, suggesting that the elderly adults were less likely to approach their individual pain thresholds. The evaluation of perception of pain on the $100 \mathrm{~mm}$ pain scale also supports this conclusion. In the younger age group, the scores on the pain scale changed significantly between pre- and post-test, from $86 \pm 14 \mathrm{~mm}$ to $93 \pm 10 \mathrm{~mm}$, an increase of $9.5 \%$ $\left(\mathrm{t}_{\text {young }}(12)=-2.4, \mathrm{p}<0.05\right)$. In the older group, the change was not significant (increasing by $8.6 \%$ from $82 \pm 10 \mathrm{~mm}$ to $88 \pm$ $\left.5 \mathrm{~mm} ;\left(\mathrm{t}_{\text {old }}(11)=-2.04, \mathrm{p}=0.72\right)\right)$.

Passive elastic stiffness describes the physiological response of a muscle during a stretch. The result shows that in both age groups, stiffness decreases between $20^{\circ}$ and $50^{\circ}$ hip flexion angle. However, the change was not significant between pre- and post-measurement or between the age groups. LaRoche et al. ${ }^{24)}$ reported a similar result, with a decrease in stiffness measured in young people at a hip flexion angle between $50^{\circ}$ and $85^{\circ}$ following a four-week stretch training of the hamstring that was not significant compared to the change in a control group. The only study to document a significant decrease was that of Marshall et al. ${ }^{22}$, who measured stiffness of the hamstring at a hip flexion angle between $20^{\circ}$ and $50^{\circ}$ after a four-week stretch training. However, these authors point out that, in their study, the stretch training was unusually extensive in contrast to other studies; the training included a total of four exercises, each repeated $3 \times 30$ seconds on five days each week. In this present study, only one exercise was repeated three times weekly for $3 \times 30$ seconds. In a study by Gajdosik et al. ${ }^{15)}$, stiffness increased in the latter half of the stress-strain curve after an eight-week stretch training of the calf muscles in elderly subjects. The available evidence regarding stiffness is equivocal; one reason for this is that stiffness is not consistently defined. Standardised angles of the stress-strain curve are often used, but these lie below the linear region ${ }^{20)}$. Even in this present study, a standardised range for the joint angle was specified, although this may not be assigned to the linear region of the curve. Future studies should therefore avoid an absolute range for the joint angle and instead should utilise individual RoM-values that are as close as possible to the maximum range of motion and hence are located within the linear or elastic region of the curve. One possibility is to define stiffness as the last $10 \%$ of the full range of motion ${ }^{25}$.

In addition to stiffness, the area under the stress-strain curve represents another elastic parameter known as passive elastic energy. After a 10-week stretch training, there was a significant increase between the pre- and post-test in both age groups. The difference between age groups was not significant. Hence, the hamstring in both age groups was capable of absorbing more passive elastic energy after a long-term stretch training. At pre- and post-test, the younger group was better able to absorb passive elastic energy, and the changes between pre- and post-test were also greater in the younger group. Magnusson et al. ${ }^{26)}$ studied the stiffness of and energy absorbed by the hamstring during stretching in long-distance runners with normal and lower flexibility of these muscles. They found that the muscles of runners with lower flexibility could absorb less energy, and stiffness was greater compared to participants with normal flexibility. These results are consistent with those of this present study, where less passive elastic energy and higher stiffness was recorded in the older experimental group. Improvement in passive elastic energy was greater in the younger group, although the older age group also showed significant improvement between pre- and post-test results.

Analyses of muscle elastic properties (stiffness and passive elastic energy) are carried out, depending on the range of motion (joint angle) and the resistance to stretch (e.g., passive torque) at a respective joint angle. This dependency must be accounted for when considering results of studies. Various results depend on whether a muscle stretch is performed to a range of motion that is at or below maximum. Magnusson ${ }^{27)}$ (p. 72) described this dilemma: “... for a given joint angle, tight subjects display greater stiffness and therefore more energy will be absorbed by the tissue. On the other hand, at a maximal joint angle normal subjects achieve a greater maximal torque and maximal stiffness and can therefore absorb more energy at this point than tight subjects."

To date, there have been no studies of the passive properties of muscles during a long-term stretch training that have compared younger versus older individuals. In summary, this study demonstrated that age has a negative effect on the maximum range of motion, maximum passive torque, passive elastic stiffness and passive elastic energy of the hamstring. It can be concluded that changes of range of motion - respectively, the elasticity of the hamstring following a 10-week stretch training - were similar in older and younger individuals. Because both groups in this study were identified as recreational athletes, the results cannot be directly carried over to the general population. Future studies should investigate the changes in individuals with no athletic background. In addition, analyses of the elastic parameters of muscle should utilise consistent definitions of terms. For example, stiffness should be defined within the linear region and should be drawn from as close as possible within the individual maximum range of motion.

\section{Conflict of interest}

The authors have no conflict of interest to declare. 


\section{ACKNOWLEDGEMENT}

We would like to thank Dr. Markus Schwarz and Christian Kaczmarek (M.Sc.) for their support with the preventative sports group.

\section{REFERENCES}

1) Alter MJ: Science of flexibility. Champaign: Human Kinetics, 2004.

2) Butler DL, Grood ES, Noyes FR, et al.: Biomechanics of ligaments and tendons. Exerc Sport Sci Rev, 1978, 6: 125-181. [Medline]

3) Hansen KA, Weiss JA, Barton JK: Recruitment of tendon crimp with applied tensile strain. J Biomech Eng, 2002, 124: 72-77. [Medline] [CrossRef]

4) Dourte LM, Kuntz AF, Soslowsky LJ: Twenty-five years of tendon and ligament research. J Orthop Res, 2008, 26: 1297-1305. [Medline] [CrossRef]

5) Curwin S: Joint structure and function. In: Levangie PK, Norkin CC (eds.), Joint structure and function. A comprehensive analysis. Philadelphia: F.A. Davis, 2005, pp 69-111.

6) Marshall PW, Siegler JC: Lower hamstring extensibility in men compared to women is explained by differences in stretch tolerance. BMC Musculoskelet Disord, 2014, 15: 223. [Medline] [CrossRef]

7) Weppler CH, Magnusson SP: Increasing muscle extensibility: a matter of increasing length or modifying sensation? Phys Ther, 2010, 90: 438-449. [Medline] [CrossRef]

8) Frankel JE, Bean JF, Frontera WR: Exercise in the elderly: research and clinical practice. Clin Geriatr Med, 2006, 22: 239-256, vii. [Medline] [CrossRef]

9) Holland GJ, Tanaka K, Shigematsu R, et al.: Flexibility and physical functions of older adults: a review. J Aging Phys Act, 2002, 10: 169-206. [CrossRef]

10) Nonaka H, Mita K, Watakabe M, et al.: Age-related changes in the interactive mobility of the hip and knee joints: a geometrical analysis. Gait Posture, 2002, 15: 236-243. [Medline] [CrossRef]

11) Ryan ED, Herda TJ, Costa PB, et al.: Acute effects of passive stretching of the plantarflexor muscles on neuromuscular function: the influence of age. Age (Dordr), 2014, 36: 9672. [Medline] [CrossRef]

12) Wydra G: Die Trainierbarkeit der Beweglichkeit in der Lebensspanne. Reanalyse vorliegender Studien unter Alternsgesichtspunkten. pt. Z Physiother, 2008, 60: $1312-1331$.

13) Faul F, Erdfelder E, Buchner A, et al.: Statistical power analyses using G*Power 3.1: tests for correlation and regression analyses. Behav Res Methods, 2009, 41: 1149-1160. [Medline] [CrossRef]

14) Schönthaler SR, Ohlendorf K: Biomechanische und neurophysiologische Veränderungen nach ein- und mehrfach seriellem passiv-statischem Beweglichkeitstraining. Köln: Sport und Buch Strauss, 2002.

15) Gajdosik RL, Vander Linden DW, McNair PJ, et al.: Effects of an eight-week stretching program on the passive-elastic properties and function of the calf muscles of older women. Clin Biomech (Bristol, Avon), 2005, 20: 973-983. [Medline] [CrossRef]

16) Hoge KM, Ryan ED, Costa PB, et al.: Gender differences in musculotendinous stiffness and range of motion after an acute bout of stretching. J Strength Cond Res, 2010, 24: 2618-2626. [Medline] [CrossRef]

17) Garber CE, Blissmer B, Deschenes MR, et al. American College of Sports Medicine: American College of Sports Medicine position stand. Quantity and quality of exercise for developing and maintaining cardiorespiratory, musculoskeletal, and neuromotor fitness in apparently healthy adults: guidance for prescribing exercise. Med Sci Sports Exerc, 2011, 43: 1334-1359. [Medline] [CrossRef]

18) Feland JB, Myrer JW, Schulthies SS, et al.: The effect of duration of stretching of the hamstring muscle group for increasing range of motion in people aged 65 years or older. Phys Ther, 2001, 81: 1110-1117. [Medline]

19) Decoster LC, Cleland J, Altieri C, et al.: The effects of hamstring stretching on range of motion: a systematic literature review. J Orthop Sports Phys Ther, 2005, 35: 377-387. [Medline] [CrossRef]

20) Knudson D: The biomechanics of stretching. J Exerc Sci Physiother, 2006, 2: 3-12.

21) Haab T, Schmid S, Sahner D, et al.: Ausgleich einer Longitudinalverschiebung des Beines an einem apparativen Straight-Leg-Raise-Test. In: Könecke T, Preuß H, Schöllhorn WI (eds.), Moving minds_crossing boundaries in sport science. Hamburg: Feldhaus, 2015, p 326.

22) Marshall PW, Cashman A, Cheema BS: A randomized controlled trial for the effect of passive stretching on measures of hamstring extensibility, passive stiffness, strength, and stretch tolerance. J Sci Med Sport, 2011, 14: 535-540. [Medline] [CrossRef]

23) Cohen J: A power primer. Psychol Bull, 1992, 112: 155-159. [Medline] [CrossRef]

24) LaRoche DP, Connolly DA: Effects of stretching on passive muscle tension and response to eccentric exercise. Am J Sports Med, 2006, 34: 1000-1007. [Medline] [CrossRef]

25) Reid DA, McNair PJ: Passive force, angle, and stiffness changes after stretching of hamstring muscles. Med Sci Sports Exerc, 2004, 36: 1944-1948. [Medline] [CrossRef]

26) Magnusson SP, Simonsen EB, Aagaard P, et al.: Determinants of musculoskeletal flexibility: viscoelastic properties, cross-sectional area, EMG and stretch tolerance. Scand J Med Sci Sports, 1997, 7: 195-202. [Medline] [CrossRef]

27) Magnusson SP: Passive properties of human skeletal muscle during stretch maneuvers. A review. Scand J Med Sci Sports, 1998, 8: 65-77. [Medline] [CrossRef] 